\title{
Segmenting the toy industry: a study of pre-teen Millennials
}

\author{
Anthony Patino \\ Department of Marketing \& Entrepreneurship, University of Baltimore, Baltimore, Maryland, USA \\ Velitchka D. Kaltcheva \\ Department of Marketing, Loyola Marymount University, Los Angeles, California, USA, and \\ David Lingelbach and Dennis A. Pitta \\ Department of Marketing \& Entrepreneurship, University of Baltimore, Baltimore, Maryland, USA
}

\begin{abstract}
Purpose - The purpose of the study is to investigate the preferences of young Millennials for a salient product category (toys) and to investigate possible within-group differences that have relevance for marketers.

Design/methodology/approach - The study carried out analysis of commercially collected survey data (538 pre-teen Millennials) from Harris OnLine using cluster and correspondence analyses.

Findings - Segments exist within the younger Millennial cohort. Specifically, four clusters emerged including enthusiasts, social/intellectuals, creatives and the disengaged.

Research limitations/implications - One limitation is the selection of the toy characteristics included in the cluster variate, which were based on scarce published research and the opinion of Harris On-Line experts. A second limitation is that the toys were never differentiated between traditional toys and electronic toys. A third limitation revolves around the maturation of the Millennials and how that may affect the clusters over time.

Practical implications - The cohorts are not homogeneous and the marketers should attend to the differences within the Millennial cohort when preparing promotions and in new product development.

Originality/value - To date, few, if any, academic studies have been done that segment the Millennial generational cohort. The research paper utilizes both cluster and correspondence analyses, which are the most appropriate for investigating segmentation in this setting.
\end{abstract}

Keywords Millennials, Cluster analysis, Segmentation, Generations, Market segmentation

Paper type Research paper

An executive summary for managers and executive readers can be found at the end of this article.

\section{Introduction}

Understanding generational attitudes is an integral component of consumer marketing research. Much research, therefore, has been devoted to understanding generational age groups in marketing over the years, with studies conducted on Baby Boomers (Coleman et al., 2006; Howarton and Lee, 2010; Yang and Jolly, 2008) and Generation X'ers (Martin and Prince, 2008; Wolburg and Pokrywczynski, 2001; Zhang, 2010). Research is just beginning to be published regarding Millennials, including studies on wine consumption (Bruwer et al., 2011), workplace issues (Myers and Sadaghiani, 2010), and fashion marketing (Moore and Carpenter, 2008). Although limited research in the academic circles has embraced Millennials, trade journals have been more receptive to research concentrating on this large generational cohort (Smith and Clark, 2010). Given the

The current issue and full text archive of this journal is available at www.emeraldinsight.com/0736-3761.htm

Journal of Consumer Marketing

29/2 (2012) 156-162

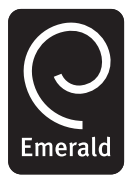

Limited [ISSN 0736-3761]

[DOI 10.1108/07363761211206401] large size of the Millennial generation, increased attention is needed to better understand the behavior and attitudes of such a significant age group.

The Generational Cohort Theory is often utilized to inform research into generational differences (Dou et al., 2006). The Generational Cohort Theory (Inglehart, 1977) states that events of national significance act as the impetus to change in generational values. This theory is based on two key assumptions: socialization and scarcity. With socialization, values are formed during adolescence and early adulthood and remain generationally stable throughout life. According to Inglehart (1981), earlier socialization is more important and "carry(ies) greater weight than later socialization" (p. 881). Scarcity implies that a generation's values are based on the limited socioeconomic resources encountered during adolescence and early adulthood (Abramson and Inglehart, 1995; Rogler, 2002). For instance, values held during more prosperous times will differ from values expressed during a recessionary period.

\section{Millennials}

The Millennial generation includes what many researchers have labeled Generation Y. It is a unique group of young people. According to Howe and Strauss (2000) in their book Millennials Rising: The Next Great Generation, "Millennial attitudes and behaviors represent a sharp break from Generation $\mathrm{X}$, and are running exactly counter to trends 
launched by the baby boomers. (p. 7)" The Millennial generation, for the most part, was born anytime between 1982 and the early 2000's, accounting for a vast number of people. In sheer numbers, Millennials total over 90 million, which is a third larger than Baby Boomers (Howe and Strauss, 2007). In fact, the Millennials are the most diverse generation, with Latinos and Asians accounting for a majority of the numbers.

According to Howe and Strauss (2007), seven core traits typify the Millennial generation. They are:

1 Special - Millennials feel they are the vital part of the future by the way they dominate America's agenda.

2 Sheltered - Millennials have been protected by their parents, government and teachers.

3 Confident - Millennials have high levels of trust and optimism.

4 Team-oriented - Millennials have developed team-oriented skills due to learning and community service.

5 Conventional-Millennials provide a unique perspective to traditional beliefs.

6 Pressured - due to influence from parents, Millennials feel pressure to excel.

7 Achieving - Millennials have become a generation focused on achievement.

One issue with Howe and Strauss' (2007) initial conceptualization is a focus on the generational cohort as a whole. Their description of what constitutes a generation states that:

[i]t is shaped by events or circumstances according to which phase of life its members occupy at the time. As each generation ages into the next phase from youth to young adulthood to midlife to elderhood - its attitudes and behaviors mature, producing new currents in the public mood (p. 42).

The between-group differences are apparent and important (Ng et al. 2010). However, the dynamics of the forces, which shape the cohort create within-group differences. Research is currently attempting to address the "maturation" effect within the cohort. There is an acknowledgement that members of a generation develop their attitudes and skills as they get older (Bergman et al., 2011) or in response to acute environmental conditions (Hauw and Vos, 2010).

Just as researchers have done with Baby Boomers, because of the large span of years, Millennials do not act alike and need to be sub-segmented (Morgan and Levy, 2002; Reisenwitz and Iyer, 2007). For instance, Baby Boomers, according to some studies, have been sub-segmented into two groups - Older Baby Boomers (Vietnam Group) and Younger Baby Boomers (the Me Group) (Morton, 2001). Millennials also need a similar sub-segmentation with older Millennials representing one segment and the younger Millennials representing the second segment. Researchers, however, disagree as to how to divide this large Millennial generation. Many industries have seen differences in the way younger and older Millennials behave. One such industry that has undergone an evolution because of differences in the Millennial cohort - older Millennials differing greatly from younger Millennials - is the toy industry (Byrne, 2005).

\section{The toy industry}

According to the Research and Markets Report for 2011, the toy industry has total revenues of over 20 billion dollars (Marketing Business Weekly, 2011). While this industry has undertaken consumer research studies regarding overall behavior and special studies on gift giving (Clarke and McAuley, 2010), limited studies have addressed Millennials. In particular, a lack of attention to the younger Millennials creates problems for the toy industry because this is the age group toy companies are currently targeting. It is, therefore, important to examine the toy preferences of young Millennials and to identify segments with respect to preferences within that age group. To our knowledge, no such segmentation research has been reported in the literature.

Market segmentation strategies are management strategies whereby information about market segments is used in designing products and creating advertising that appeals to those segments (Dickson and Ginter, 1987). Market segmentation is not only used in formulating marketing strategy; it can also be used for research analysis (Dickson and Ginter, 1987; Kimiloglu et al., 2010). The use of market segmentation has often been the subject of investigation in areas such as advertising research (Dubow, 1992; Stanley et al., 1987) and product clustering (Kimiloglu et al., 2010). In the next section, we describe a study using a representative sample of young Millennials (eight through 12 years old) that identifies toy-preference segments. We first describe the sample and the study design along with the measures. The paper concludes with a discussion of the results of this research, its limitations, and implications for marketers.

\section{Study}

\section{Respondents}

A representative national sample of 538 pre-teen Millennials completed online surveys. The sample was obtained from the Harris Poll On-Line (HPOL) opt-in panel which is representative of the US population with reference to age, gender, race, and geographic location. Data were collected from five pre-teen years (eight through 12). Respondents were recruited through an initial email contact with their parents. Parents who received the invitation email were asked to forward the survey to their child(ren) after giving consent for their child(ren)'s participation.

\section{Measures}

On a five-point scale, anchored between "very unimportant" and "very important," respondents rated the importance of each of the following characteristics of their favorite toy: "challenging," "easy to use," "made me use my imagination" (creative), "taught me something" (educational), and "allowed me to play with others" (social). The five toy characteristics that were evaluated and included in the cluster analysis were selected based on the toy literature and prior research (James, 2005; Poris, 2005). The measurement scales were developed and validated by experts at Harris Interactive.

\section{Results}

A two-stage cluster analysis (a hierarchical followed by a nonhierarchical algorithm) was conducted in SAS 9.2. With its objective of identifying "homogenous groups that are as distinct between one another as possible," cluster analysis offers a methodology uniquely suitable for developing taxonomies with maximum managerial relevance (Hair et al., 2010 , p. 519). In fact, cluster analysis has been used regularly 
by both academics and practitioners for segmentation in marketing (Punj and Stewart, 1983; Wind, 1978).

First, we checked for multicollinearity among the five variables to be included in the cluster variate because highly correlated variables - if such exist in the data - would influence the cluster solution more than uncorrelated variables. The highest bivariate correlation was .50 (between the Challenging and Educational characteristics) suggesting the absence of multicollinearity (Hair et al. 2010) (see Table I). Next, we checked for outliers and no such observations were detected in the data.

We first completed a hierarchical cluster analysis to determine the number of clusters. In order to increase our confidence in the solution, we decided to conduct two analyses using different hierarchical algorithms. Because of the multivariate nature of the data, we used the EqualVariance Maximum Likelihood (EML) and Ward's Minimum-Variance methods. At each agglomerative step, Ward's method combines the two clusters whose combination results in the smallest increase in the within-cluster error sum of squares across all variables and formed clusters. Ward's algorithm tends to create clusters with approximately the same number of observations. The EML algorithm maximizes the likelihood at each level of the hierarchy and is similar to the Ward's method, but removes the bias toward equally sized clusters. The two algorithms produced similar results, both suggesting a four-cluster solution.

Next, we conducted a non-hierarchical cluster analysis using random software-selected seeds. The clusters are profiled in Table II and Figure 1. The variables were standardized prior to the cluster analysis and therefore their means are zero. The positive (negative) variable values indicate the number of standard deviations above (below) the mean. There are significant differences among the clusters for all five variables $(F(3,534) \leq 90.38, p<0.0001)$ (Table II).

The largest cluster - the Enthusiasts (44 percent) - is distinguished by high means on all four variables suggesting that the respondents belonging to this cluster are enthusiastic users of a wide variety of toys. The members of the Social \& Intellectual cluster (22 percent) have high means for the Challenging and Social characteristics and low means on the other characteristics, thus expressing preference for toys that are challenging and allow them to play with others. The Creatives (19 percent) like easy-to-use toys that inspire their imagination. Finally, the Disengaged cluster (15 percent) is distinguished by low means on all variables suggesting no interest for playing with toys.

To evaluate the stability of the cluster solution, we reordered the observations in the dataset in the reverse order and subsequently performed the cluster analysis once again (Hair et al., 2010). This second analysis produced a similar solution. A cross-classification of cluster membership yielded a high number of matches suggesting that the observations that cluster together in the first analysis are likely to cluster together in the second solution as well (see Table III).

Correspondence analysis was conducted after the cluster analysis to examine the demographics of the four clusters. Correspondence analysis is an increasingly popular interdependence technique for analyzing contingency tables and identifying relationships among objects and/or variables. It creates maps such that objects and/or variables are simultaneously plotted on the same map directly based on their association (Hair et al., 2010; Myers and Mullet, 2003). In this research, we employ correspondence analysis to identify the relationship among the four clusters and ten demographic categories (Gender: male/female $\times$ Age: 8, 9, 10,11 , and 12 years old).

The correspondence analysis map is displayed in Figure 2. We see that the first two dimensions account for 95.16 percent of the variance. Dimension 1 explaining 69.21 percent of the variance is defined between the Creatives cluster at one extreme and the Social \& Intellectual cluster at the other extreme. We can therefore call this dimension

Table I Means, standard deviations, and correlations

\begin{tabular}{|c|c|c|c|c|c|c|c|}
\hline & Means & Standard deviations & Creative & Challenging & $\begin{array}{l}\text { Correlations } \\
\text { Educational }\end{array}$ & Easy to use & Social \\
\hline Creative & 3.70 & 1.24 & 1.00 & & & & \\
\hline Challenging & 3.68 & 1.26 & 0.06 & 1.00 & & & \\
\hline Educational & 3.26 & 1.26 & 0.33 & 0.50 & 1.00 & & \\
\hline Easy to use & 4.07 & 0.98 & 0.33 & -0.01 & 0.21 & 1.00 & \\
\hline Social & 3.77 & 1.28 & 0.07 & 0.23 & 0.23 & 0.25 & 1.00 \\
\hline
\end{tabular}

Table II Cluster profiles

\begin{tabular}{|c|c|c|c|c|c|c|c|}
\hline \multirow[b]{2}{*}{ CLUSTERS } & \multirow[b]{2}{*}{$n$} & \multirow[b]{2}{*}{$\%$} & \multicolumn{5}{|c|}{ Standardized cluster means } \\
\hline & & & Creative & Challenging & Educational & Easy to use & Social \\
\hline Enthusiasts & 238 & 44 & 0.53 & 0.61 & 0.74 & 0.37 & 0.25 \\
\hline Social and Intellectual & 119 & 22 & -1.07 & 0.19 & -0.45 & -0.28 & 0.56 \\
\hline Creatives & 100 & 19 & 0.56 & -1.47 & -0.74 & 0.51 & -0.27 \\
\hline Disengaged & 81 & 15 & -0.67 & -0.26 & -0.60 & -1.31 & -1.23 \\
\hline Total & 528 & 100 & 0.00 & 0.00 & 0.00 & 0.00 & 0.00 \\
\hline$F$ value & & & 181.10 & 250.80 & 139.81 & 111.68 & 90.38 \\
\hline$P$ value & & & $<0.0001$ & $<0.0001$ & $<.0001$ & $<0.0001$ & $<0.0001$ \\
\hline
\end{tabular}


Figure 1 Cluster profiles

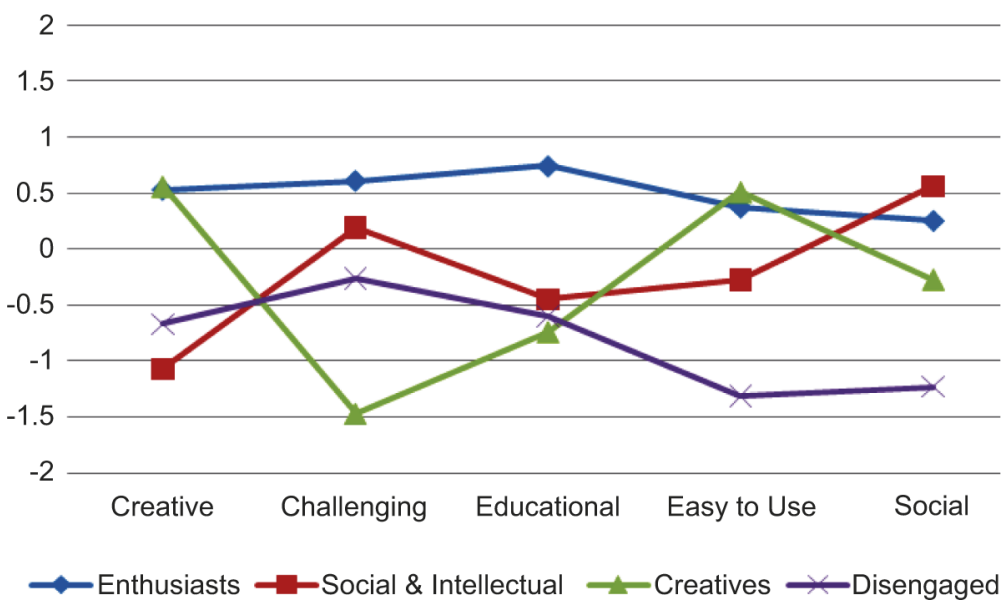

Table III Cross-classification of cluster membership

\begin{tabular}{|c|c|c|c|c|c|}
\hline \multirow[b]{2}{*}{ Original order } & \multirow[b]{2}{*}{ Enthusiasts } & \multicolumn{2}{|c|}{ Reverse order } & \multirow[b]{2}{*}{ Disengaged } & \multirow[b]{2}{*}{ Tota } \\
\hline & & Social and Intellectual & Creatives & & \\
\hline Enthusiasts & 228 & 1 & 0 & 9 & 238 \\
\hline Social and Intellectual & 12 & 83 & 0 & 24 & 119 \\
\hline Creatives & 4 & 7 & 89 & 0 & 100 \\
\hline Disengaged & 0 & 6 & 2 & 73 & 81 \\
\hline Total & 244 & 97 & 91 & 106 & 538 \\
\hline
\end{tabular}

Figure 2 Correspondence analysis results

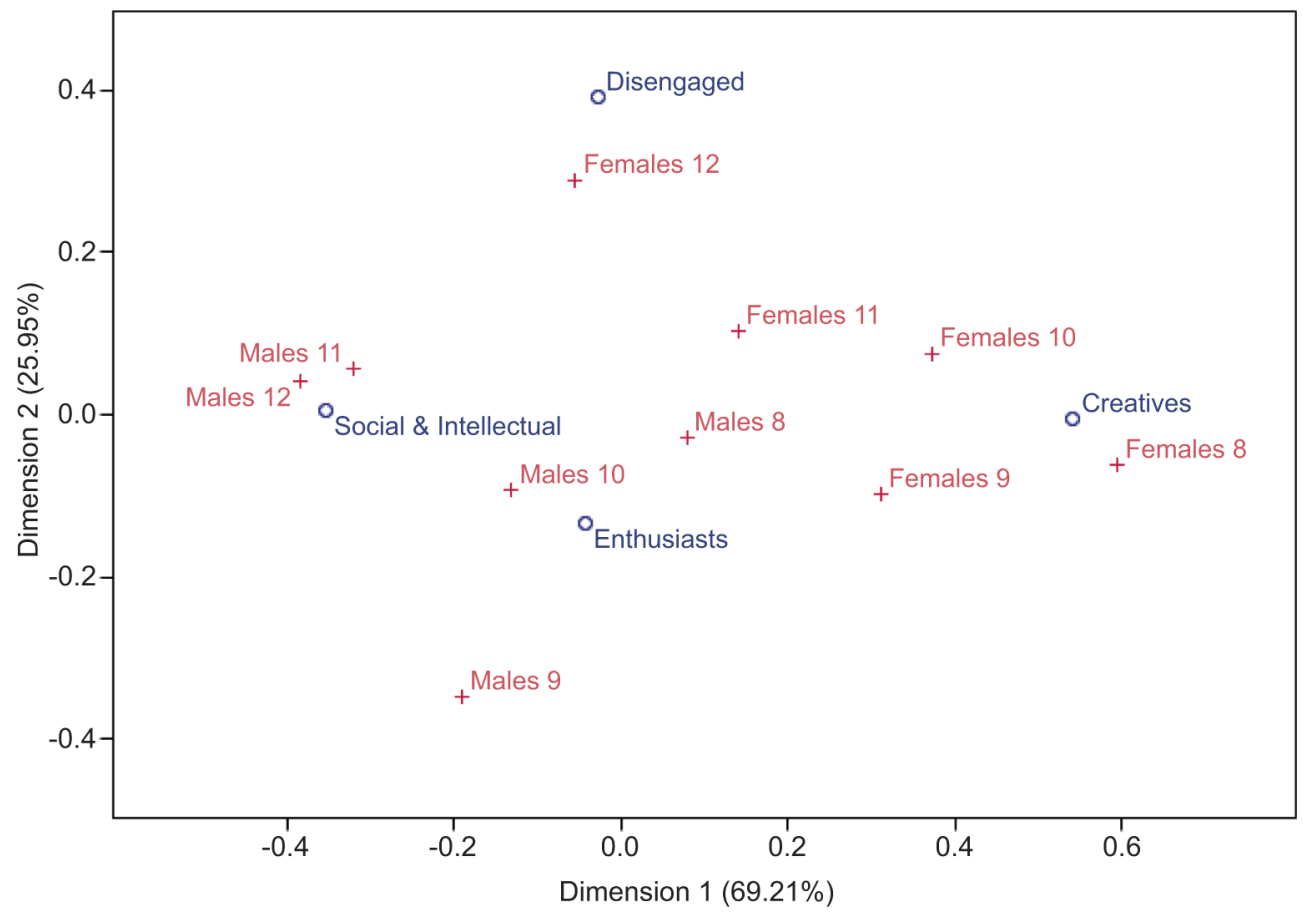


"Creative vs Intellectual." The second dimension explaining 25.95 percent of the variance is described by the Enthusiasts cluster at one end and the Disengaged cluster at the other end, thus representing the level of enthusiasm for playing with toys (the Enthusiasm Dimension).

When we examine the demographic categories we see that younger girls (eight through ten years old) seem to be located close to the Creative end of Dimension 1 and in the moderate range of the Enthusiasm dimension (Dimension 2). In contrast, the older girls (especially those 12 years old) are closer to the low enthusiasm end of Dimension 2. The younger boys ( 8 through 10 years old) are moderate to high on enthusiasm and in the middle range of the Creative vs. Intellectual dimension, whereas boys aged 11 and 12 are moderate on enthusiasm and close to the Intellectual end of Dimension 1.

\section{Discussion}

The cluster and correspondence analyses suggest age $\mathrm{x}$ gender differences in toy preferences among pre-teen Millennials. While all Millennial pre-teens mature in their preferences for toys, males and females exhibit dissimilar preferences from the early pre-teen ages and those differences continue as toy preferences evolve. Girls seem more likely to pursue creativity in play and therefore express preferences for toys inspiring their imagination. Girls' enthusiasm for toys ranges from moderate in the younger ages to low in older age. In contrast, boys continue to be at least moderately enthusiastic about playing with toys throughout their pre-teen years. Unlike girls, boys gravitate more towards challenging toys that allow them to play with others.

\section{Implications for marketers}

The results and conclusions of this study will enable toy companies to better understand what drives this generational cohort of pre-teen Millennials. Perhaps the most important implication of this research is that marketers need to do what they normally do, namely, look deeply for differences in any target audience. Treating generational groups as unitary cohorts is imprecise and may miss important differences that can be vital to new product and service success. For example, the finding that pre-teen Millennial girls prefer creativity in play can guide product development strategy to enhance the fit between this group's preferences and new toys. Furthermore, toy companies' research and development teams can engage in less risky product introductions by overlapping the segmentation variables with the traits typifying Millennials. For example, the development of intellectual toys can be more efficiently targeted toward preteen Millennial boys by understanding that male Millennials have a need to excel.

One additional implication concerns the acute effects that shape generational cohorts. The Millennial cohort's size, orientation toward achievement, and energy make it an attractive target for marketers. This research highlights the importance of studying the group carefully to exploit the potential it presents. Citations above note the formative influence of events such as September 11 2001. More recently, events such as the 2008 US presidential election and continuing economic recession affect Millennials' perceptions, attitudes and expectations. Astute marketers will be aware of formative events and will assess the effects of these events on target consumers. It may be prudent for marketers who choose to target Millennials to create research task teams to keep the organization's finger on the cohort's pulse.

\section{Limitations and future research}

One limitation of this research is that the selection of the toy characteristics influences the cluster analysis solution. Although the five toy characteristics evaluated in this research were selected based on the literature, it is conceivable that other characteristics may be important for pre-teen Millennials. Another limitation concerns the growth of electronic toys, video games and other forms of entertainment. Both these limitations present opportunities for future research, which may examine other toy characteristics as well as segment Millennials with respect to electronic toys, video games and other forms of entertainment. In addition, tracking preferences over time may add to the understanding of maturation effects, the cumulative effects of environmental factors on the cohort, which may impact the clusters over time.

Then too, only one segment, young Millennials, was studied. Although toy use seems ideally focused on this segment, it is possible that older Millennials exhibit their own preferences toward toys. It is likely that the toys will be different, possibly taking the form of golf clubs, automobiles or other items. It would be interesting to investigate whether the clusters uncovered in the research apply to older Millennials as well.

\section{References}

Abramson, P.R. and Inglehart, R. (1995), Value Change in Global Perspective, University of Michigan Press, Ann Arbor, MI.

Bergman, S., Fearrington, M., Davenport, S. and Bergman, J. (2011), "Millennials, narcissism, and social networking: what narcissists do on social networking sites and why", Personality \& Individual Differences, Vol. 50 No. 5, pp. 706-11.

Bruwer, J., Saliba, A. and Miller, B. (2011), "Consumer behaviour and sensory preference differences: implications for wine product marketing", fournal of Consumer Marketing, Vol. 28 No. 1, pp. 5-18.

Byrne, C. (2005), "Hot toys are dead: long live hot products", Young Consumers, Vol. 7 No. 1, pp. 8-13.

Clarke, P. and McAuley, A. (2010), "Parental evaluation of popular brand names given as Christmas gifts and sources of information used in these decisions", fournal of Consumer Marketing, Vol. 27 No. 6, pp. 534-42.

Coleman, L.J., Hladikova, M. and Savelyeva, M. (2006), "The baby boomer market", fournal of Targeting, Measurement and Analysis for Marketing, Vol. 14 No. 3, pp. 191-209.

Dickson, P.R. and Ginter, J.L. (1987), "Market segmentation, product differentiation, and marketing strategy", fournal of Marketing, Vol. 51 No. 2, pp. 1-10.

Dou, W., Wang, G. and Zhou, N. (2006), “Generational and regional differences in media consumption patterns of Chinese Generation X consumers", fournal of Advertising, Vol. 35 No. 2, pp. 101-10. 
Dubow, J.S. (1992), "Occasion-based vs user-based benefit segmentation: a case study", fournal of Advertising Research, Vol. 32 No. 2, pp. 11-18.

Hair, J.F. Jr, Black, W.C., Babin, B.J. and Anderson, R.E. (2010), Multivariate Data Analysis, 7th ed., Prentice Hall, Upper Saddle River, NJ.

Hauw, S. and Vos, A. (2010), “Millennials' career perspective and psychological contract expectations: does the recession lead to lowered expectations?", Fournal of Business Eo Psychology, Vol. 25 No. 2, pp. 293-302.

Howarton, R. and Lee, B. (2010), "Market analysis of fit preferences of female boomers", fournal of Fashion Marketing and Management, Vol. 14 No. 2, pp. 219-29.

Howe, N. and Strauss, W. (2000), Millennials Rising: The Next Great Generation, Vintage, New York, NY.

Howe, N. and Strauss, W. (2007), Millennials Go to College: Strategies for a New Generation on Campus, Life Course Associates, Great Falls, VA.

Inglehart, R. (1977), The Silent Revolution: Changing Values and Political Styles among Western Publics, Princeton University Press, Princeton, NJ.

Inglehart, R. (1981), "Post-materialism in an environment of insecurity", American Political Science Review, Vol. 75, December, pp. 880-900.

James, A.J. (2005), "Unlocking the secret world of kids' imagination", Young Consumers, Vol. 7 No. 1, pp. 25-8.

Kimiloglu, H., Nasir, V.A. and Nasir, S. (2010), "Discovering behavioral segments in the mobile phone market", fournal of Consumer Marketing, Vol. 27 No. 5, pp. 401-13.

Marketing Business Weekly (2011), "Research and Markets 2011 report on the US $\$ 20$ billion toy and game manufacturing industry", Marketing Business Weekly, Vol. 63.

Martin, N. and Prince, D. (2008), "Factoring for X: an empirical study of Generation X's materialistic attributes", Fournal of Management and Marketing Research, Vol. 1, pp. 65-78.

Moore, M. and Carpenter, J.M. (2008), "Intergenerational perceptions of market cues among US apparel consumers", Fournal of Fashion Marketing and Management, Vol. 12 No. 3, pp. 323-37.

Morgan, C.M. and Levy, D.J. (2002), "The boomer attitude", American Demographics, Vol. 24 No. 9, pp. 42-5.

Morton, L.P. (2001), "Segmenting baby boomers", Public Relations Quarterly, Vol. 46 No. 3, pp. 46-7.

Myers, J.H. and Mullet, G.M. (2003), Managerial Applications of Multivariate Analysis in Marketing, American Marketing Association, Chicago, IL.

Myers, K. and Sadaghiani, K. (2010), "Millennials in the workplace: a communication perspective on Millennials' organizational relationships and performance", fournal of Business and Psychology, Vol. 25 No. 2, pp. 225-38.

Ng, E.S.W., Schweitzer, L. and Lyons, S.T. (2010), "New generation, great expectations: a field study of the Millennial Generation”, fournal of Business \& Psychology, Vol. 25 No. 2, pp. 281-92.

Poris, M. (2005), "Understanding what fun means to today's kids", Young Consumers, Vol. 7 No. 1, pp. 14-22.

Punj, G. and Stewart, D.W. (1983), "Cluster analysis in marketing research: review and suggestions for applications", Fournal of Marketing Research, Vol. 20, pp. 134-48.
Reisenwitz, T. and Iyer, R. (2007), “A comparison of younger and older baby boomers: investigating the viability of cohort segmentation", The fournal of Consumer Marketing, Vol. 24 No. 4, pp. 202-13.

Rogler, L.H. (2002), "Historical generations and psychology: the case of the Great Depression and WWII", The American Psychologist, Vol. 57 No. 12, pp. 1013-23.

Smith, J. and Clark, G. (2010), "New games, different rules Millennials are in town", fournal of Diversity Management, Vol. 5 No. 3, pp. 1-11.

Stanley, T.T., Moschis, G.P. and Danko, W.D. (1987), "Financial service segments - the seven faces of the affluent market", Fournal of Advertising Research, Vol. 27 No. 4, pp. 52-67.

Wind, Y. (1978), "Issues and advances in segmentation research", Fournal of Marketing Research, Vol. 15, August, pp. 317-37.

Wolburg, J.M. and Pokrywczynski, J. (2001), “A psychographic analysis of Generation Y college students", Fournal of Advertising Research, Vol. 41 No. 5, pp. 33-52.

Yang, K. and Jolly, L.D. (2008), "Age cohort analysis in adoption of mobile data services: Gen Xers versus Baby Boomers", The fournal of Consumer Marketing, Vol. 25 No. 5, pp. 272-80.

Zhang, J. (2010), "The persuasiveness of individualistic and collectivistic advertising appeals among Chinese Generation-X consumers", Fournal of Advertising, Vol. 39 No. 3, pp. 69-80.

\section{About the authors}

Dr Anthony Patino is an Assistant Professor in the Department of Marketing and Entrepreneurship at the University of Baltimore. Anthony Patino is the corresponding author and can be contacted at: apatino@ubalt.edu

Dr Velitchka D. Kaltcheva is an Associate Professor in the Department of Marketing and Business Law at Loyola Marymount University.

Dr David Lingelbach is an Assistant Professor in the Department of Marketing and Entrepreneurship at the University of Baltimore.

Dr Dennis A. Pitta is a Professor in the Department of Marketing and Entrepreneurship at the University of Baltimore.

\section{Executive summary and implications for managers and executives}

This summary has been provided to allow managers and executives a rapid appreciation of the content of this article. Those with a particular interest in the topic covered may then read the article in toto to take advantage of the more comprehensive description of the research undertaken and its results to get the full benefits of the material present.

According to some theorists, the behavior of consumers within a specific generation is determined in part by significant events which they experience as teenagers and young adults. Such experiences socialize consumers, forming generation-wide values which prevail throughout life. The values of a particular generation are also shaped by the level of economic prosperity at the time. 
Plenty research attention has therefore been afforded to different generational groups, especially the Baby Boomer and Generation X cohorts. Studies concerning Generation Y or Millennium consumers are beginning to increase also and have addressed topics that include fashion marketing, wine consumption and workplace issues. As the number within this cohort exceeds 90 million, the marketing fraternity has an urgent need to improve understanding of its key characteristics.

It is broadly accepted that Millennials are those born between around 1980 and 2000. The generation is regarded as being the 'most diverse' and exhibit attitudes and behaviors which mark a significant departure from norms of the preceding generation. In the view of certain scholars, Millennials in the United States are conventional, teamoriented and place high value on achievement. They are also confident and regard themselves as special yet feel pressured to do well by parents who have helped to provide them with a sheltered upbringing.

A common criticism of these studies is the propensity to view generational cohorts as single entities which differ from other groups. This ignores the high probability of withingroup differences. More specifically, people within a generation become subject to additional influences that can impact on their attitudes as they mature.

Marketers are therefore urged to sub-divide Millennials in the same manner that others have done with the Baby Boomer cohort. That generation has been subsequently separated into Older Baby Boomers and Younger Baby Boomers by certain academics. Precisely how to divide the sizeable Millennial generation is, however, the subject of considerable debate among researchers.

Differences within the Generation $\mathrm{Y}$ cohort can prove significant for many business sectors. The multi-billion toy industry is a perfect example. Although studies into consumer behavior have been conducted for this industry, the focus on Millennials has been minimal. Since toy marketers are targeting younger members of this generation, it is important to identify different subgroups based on their preferences.

Given this void, Patino et al. conduct a study involving preteen Millennials between 8 and 12 years-old. The national sample of 538 was considered representative of the population in the United States with regard to age, gender, race and geographical location. Participants completed an online survey after receiving parental consent.

Prior research identified five toy characteristics to include in the study. Respondents were invited to rate the importance levels of each attribute in relation to their favorite toy. The task was essentially to indicate how challenging, easy to use, creative, educational and social they considered the toy to be.

A core aim of this study was to identify specific groups that are distinct from the others. The various analyses carried out on the data led to the classification of four separate clusters:

1 Enthusiasts. This Millennial subgroup incorporated 44 percent of subjects and was the largest. High ratings on all toy attributes revealed them to be keen about using a diverse range of toys.
Volume $29 \cdot$ Number $2 \cdot 2012 \cdot 156-162$

2 Social \& Intellectual. Ratings were high for the Challenging and Social characteristics but low on the remainder. Toys which are challenging and inspire playing with other people are therefore preferred by this cluster, which accounts for 22 percent of respondents.

3 Creatives constitute 19 percent of the sample and indicate a passion for toys which stimulate their imagination and are simple to use.

4 Disengaged. At 15 percent, this cluster is the smallest. The authors assume these children lack interest in toys because of low ratings awarded to all characteristics.

Further analysis was conducted in order to consider the demographic features of each cluster using gender and each age from 8 years-old through to 12 years-old. The first of the two dimensions identified by Patino et al. had the Creative cluster positioned at the opposite end from the Social and Intellectual cluster. Enthusiasts were at one end of the second dimension, with the Disengaged segment at the other.

Closer inspection of the dimensions showed that:

- Girls aged between 8 and 10 rate high on creativity and moderate on enthusiasm;

- Enthusiasm is lower among older girls, particularly 12 year-olds;

- Up to aged 10 , boys are moderate to high on enthusiasm and midway on the Creative-Intellectual dimension; and

- Boys who are 11 and 12 years-old are moderate on enthusiasm and have a high intellectual rating.

The results of this study reveal the impact of gender on toy preferences. Consequently, marketing to pre-teen Millennials should note the penchant among girls for toys able to rouse their imagination. Another important tendency is for girls to become progressively less enthusiastic about playing with toys as they get older. A key difference with boys is their progression towards more challenging toys that encourage them to play with others. Throughout their pre-teen stage, boys' enthusiasm for toys tends to remain moderate at least.

It will invariably be less effective when marketers view generational cohorts as homogenous. In this case, being aware of significant differences can help companies to develop new products and appropriately target relevant pre-teen clusters. The risk of failure can therefore be reduced. The authors also urge marketers to note any future major events and be alert to their formative effect on the Generation Y cohort. They cite 9/11 and the ongoing economic decline as examples that have impacted upon the 'perceptions, attitudes and expectations' of Millennials.

Further study using additional toy characteristics is suggested. Researchers might also investigate preferences in growing markets like electronic toys and video games. Another idea is to track preferences over a long period and examine any 'cumulative effects' of external factors. Whether these clusters apply to older Millennials and what preferences these consumers exhibit are other avenues to explore.

(A précis of the article "Segmenting the toy industry: a study of pre-teen Millennials". Supplied by Marketing Consultants for Emerald.) 
Reproduced with permission of the copyright owner. Further reproduction prohibited without permission. 